RESIDENT

\& FELLOW

SECTION

Section Editor

Mitchell S.V. Elkind,

MD, MS

\title{
Pearls \& Oy-sters: Optic tract syndrome
}

PEARLS

- The optic tract syndrome is characterized by a contralateral, incongruous homonymous hemianopia, contralateral relative afferent pupillary defect (RAPD), and optic atrophy due to retrograde axonal degeneration.

Address correspondence and reprint requests to Dr. Amadeo R. Rodriguez, St. Joseph's Healthcare CAHS Campus, 2757 King Street East, Hamilton, Ontario, Canada L8G 5E4 arrodr@gmail.com bowtie atrophy of the eye with temporal field the disc of the eye with nasal field loss.
- Optic disc pallor often results in a pattern of loss and atrophy of the upper and lower poles of

- Visual acuity and color vision are usually normal unless there is bilateral involvement or extension to the chiasm or optic nerve.

\section{OY-STERS}

- Homonymous hemianopia is typically incongruous in optic tract lesions although this concept only applies if the defect is incomplete. Complete homonymous hemianopia is of no localizing value.

- Behr's pupil (larger pupil on the side opposite to the lesion) and pupillary hemiakinesia (Wernicke sign) are historical signs that are not helpful in the clinical setting.

The optic tract is a white matter band that projects from the chiasm to the lateral geniculate body. Given this particular anatomy, lesions of this structure may result in several typical clinical features which are often under-recognized. We present a case of massive recurrence of an epidermoid tumor of the cerebellopontine angle that presented with manifestations of optic tract involvement.

CASE REPORT A 46-year-old man presented with several months of right visual field deficit and memory loss. He had undergone incomplete resection of an epidermoid tumor of the left cerebellopontine angle 10 years prior to this presentation. On examination, visual acuity was normal and there was an obvious right homonymous hemianopia by confrontation with pallor of the optic discs. An MRI study of the brain demonstrated a large lesion extending into the middle cranial fossa and involving the left optic tract (figure, A). He underwent surgery again and postoperative MRI showed a clear defect in the region of the left optic tract (figure, A). Pathology confirmed the recurrent nature of the epidermoid tumor.

After surgery, he was referred to ophthalmology for evaluation of a complete left third nerve palsy as a result of intraoperative damage. His postoperative visual acuity was 20/25 in both eyes with normal color vision. There was a right RAPD. Funduscopy showed optic atrophy with a bowtie pattern of the right optic disc (figure, B), whereas the left disc showed mild, diffuse pallor. Goldmann visual field examination revealed a virtually complete right homonymous hemianopia. A year after a second operation, the left third nerve palsy improved and he only had a minor elevation deficit in the left eye but no diplopia in primary gaze or reading position.

DISCUSSION The optic tract contains ipsilateral retinal temporal fibers and contralateral retinal nasal fibers which have decussated in the optic chiasm. Most of the fibers project to the lateral geniculate body. These fibers are involved in processing the contralateral visual field and thus, damage causes contralateral homonymous field defect. If incomplete, the visual field defects are incongruous (i.e., asymmetric). ${ }^{1}$ This is attributed to the fact that corresponding fibers from each eye are relatively separated anatomically in the optic tract.

The fibers contained in the optic tract are axons from the ganglion cells whose bodies are in the retina. Damage anywhere along these axons results in retrograde axonal degeneration that becomes clinically evident as pallor of the optic disc. This process typically occurs over 4 to 6 weeks.

Axons from the retina nasal to the optic disc and those corresponding to the nasal half of the macula (which are located temporal to the disc) are located mainly across the horizontal portion of the disc. 

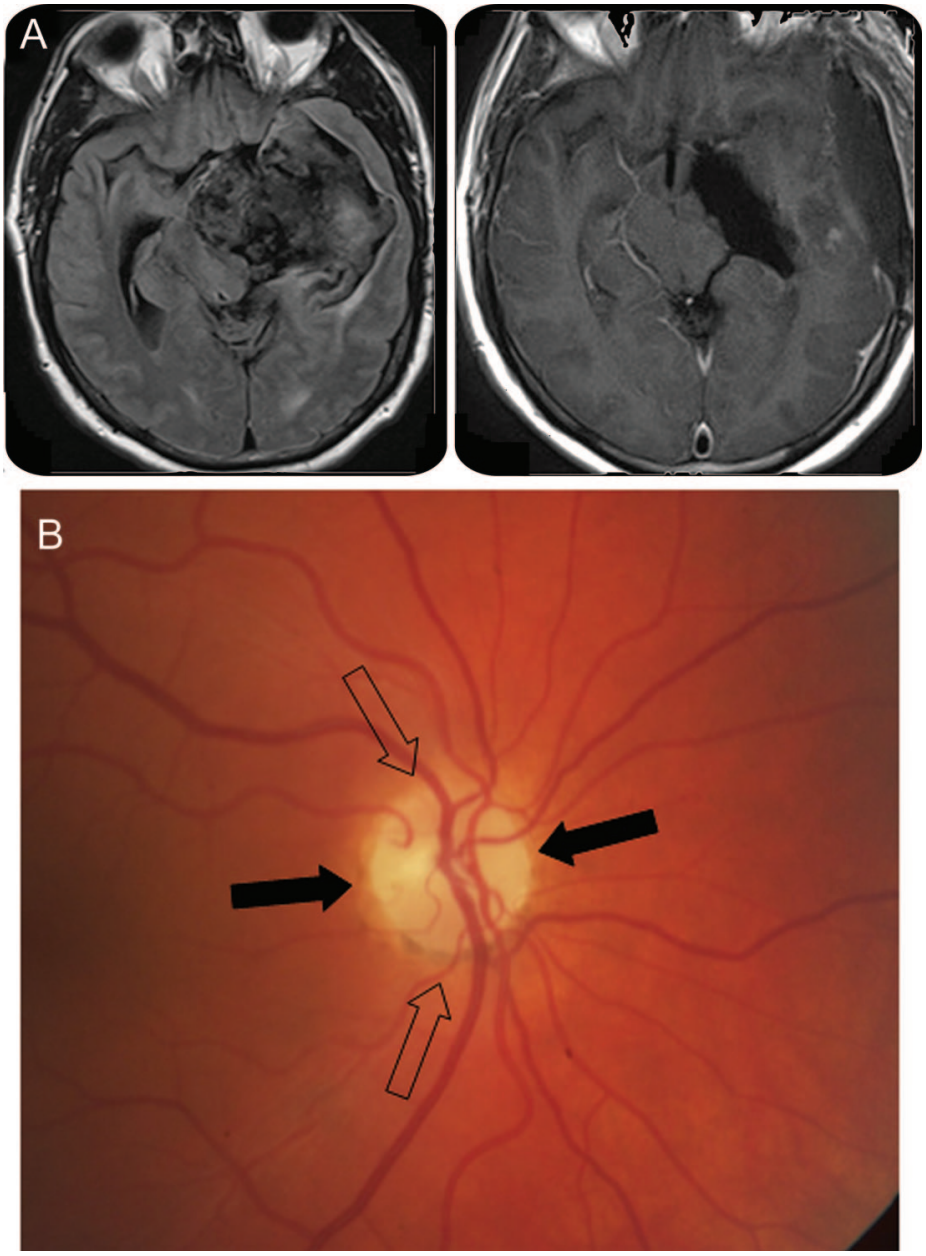

(A) Preoperative and postoperative MRI. (B) Bowtie atrophy. Fibers from the retina nasal to the optic disc and fibers nasal to the fovea but temporal to the disc project to the central portion of the optic nerve (black arrows). Fibers from the temporal retina form the poles of the optic disc (hollow arrows).

These axons subserve the entire temporal field in the contralateral eye and are destined to decussate in the chiasm. The poles of the optic disc are formed by fibers from the temporal retina (figure, B). As a consequence of this particular organization, damage to the decussating fibers results in atrophy across the central portion of the disc with sparing of the poles (bowtie atrophy), and damage to the temporal fibers mainly affects the poles with preservation of the central portion of the disc. ${ }^{2}$ It is important to remember that bowtie atrophy can be unilateral (contralateral eye in optic tract lesions) or bilateral (chiasmal lesions).

Visual acuity and color vision are usually normal in an optic tract lesion because it only affects the nasal macular fibers from the contralateral eye and the temporal macular fibers from the ipsilateral eye. In the event of bilateral involvement or extension to the chiasm or optic nerve, ${ }^{3}$ acuity and color vision become affected.

The optic tract also contains fibers involved in the pupillary light reflex. It is believed that pupillary fibers follow the same path as those involved in vision. However, pupillary fibers leave the optic tract before they reach the lateral geniculate body and project to the pretectal nuclei. Whereas in the event of incomplete optic tract damage and incongruous visual field loss, a RAPD is expected to be present in the eye with more extensive field loss, in complete lesions it is typically present in the eye with temporal field loss. This is due to the fact that the nasal retina is more extensive than the temporal retina and there are more crossed than uncrossed fibers with the proportion of decussating and nondecussating fibers estimated to be 53:47. ${ }^{4}$ As a result, each optic tract contains more pupillomotor input from the contralateral eye and lesions in this area cause a contralateral RAPD. There is evidence that the presence of a RAPD in the setting of an optic tract lesion reflects the difference in light sensitivity between the intact temporal and nasal hemifields rather than the absolute number of crossed vs uncrossed fibers. ${ }^{5}$ The recent discovery of melanopsin-expressing retinal ganglion cells that mediate the pupillary light reflex ${ }^{6}$ provides the intriguing yet unproven hypothesis that the retinal distribution of these may explain the origin of a RAPD in optic tract syndrome.

\section{DISCLOSURE}

Dr. Rodriguez received a speaker honorarium from Biogen Idec. Dr. Reddy reports no disclosures.

\section{REFERENCES}

1. Savino PJ, Paris M, Schatz NJ, Orr LS, Corbett JJ. Optic tract syndrome. Arch Ophthalmol 1978;96:656-663.

2. Unsold R, Hoyt WF. Band atrophy of the optic nerve. Arch Ophthalmol 1980;98:1637-1638.

3. Newman SA, Miller NR. Optic tract syndrome: neuroophthalmologic considerations. Arch Ophthalmol 1983; 101:1241-1250.

4. Kupfer C, Chumbley L, Downer JC. Quantitative histology of optic nerve, optic tract and lateral geniculate nucleus of man. J Anat 1967;101:393-401.

5. Kardon R, Kawasaki A, Miller NR. Origin of relative afferent pupillary defect in optic tract lesions. Ophthalmology 2006;113:1345-1353.

6. Kawasaki A, Kardon RH. Intrinsically photosensitive retinal ganglion cells. J Neuroophthalmol 2007;27:195-204. 


\title{
Neurology
}

\author{
Pearls \& Oy-sters: Optic tract syndrome \\ Amadeo R. Rodriguez and Kesava Reddy \\ Neurology 2010;75;e86-e87 \\ DOI 10.1212/WNL.0b013e3181feb454
}

This information is current as of November 22, 2010

\section{Updated Information \& Services}

References

Citations

Subspecialty Collections

Permissions \& Licensing

Reprints including high resolution figures, can be found at: http://n.neurology.org/content/75/21/e86.full

This article cites 6 articles, 0 of which you can access for free at: http://n.neurology.org/content/75/21/e86.full\#ref-list-1

This article has been cited by 1 HighWire-hosted articles: http://n.neurology.org/content/75/21/e86.full\#\#otherarticles

This article, along with others on similar topics, appears in the following collection(s):

Optic nerve

http://n.neurology.org/cgi/collection/optic_nerve

Pupils

http://n.neurology.org/cgi/collection/pupils

Visual fields

http://n.neurology.org/cgi/collection/visual_fields

Information about reproducing this article in parts (figures,tables) or in its entirety can be found online at:

http://www.neurology.org/about/about_the_journal\#permissions

Information about ordering reprints can be found online:

http://n.neurology.org/subscribers/advertise

Neurology ${ }^{\circledR}$ is the official journal of the American Academy of Neurology. Published continuously since 1951, it is now a weekly with 48 issues per year. Copyright Copyright (? 2010 by AAN Enterprises, Inc.. All rights reserved. Print ISSN: 0028-3878. Online ISSN: 1526-632X.

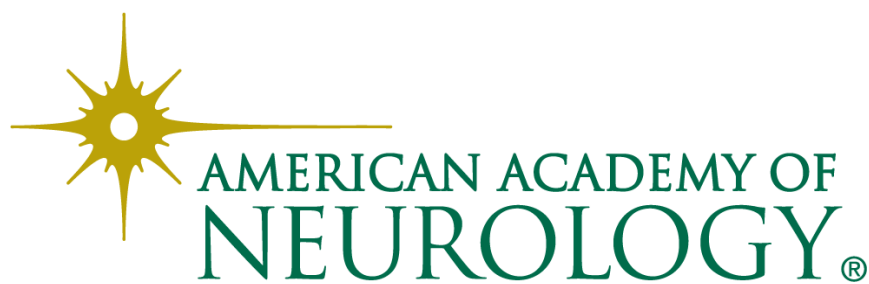

